\title{
Necrológica
}

Collectanea Botanica vol. 32 (2013): 7-8

ISSN: 0010-0730

doi: 10.3989/collectbot.2013.v32.001

\section{Pedro María Uribe-Echebarría Díaz (1953-2013)}

\author{
D. GÓMEZ
}

\begin{abstract}
Instituto Pirenaico de Ecología, av. Nuestra Señora de la Victoria, s/n, ES-22700 Jaca, España
\end{abstract}
E-mail: dgomez@ipe.csic.es

El pasado 20 de octubre falleció en Vitoria-Gasteiz, a consecuencia de un fatal atropello, Pedro María Uribe-Echebarría Díaz. Había nacido en esa misma ciudad en 1953 y allí cursó sus estudios hasta marchar a Pamplona donde obtuvo la licenciatura en Ciencias Biológicas en la Universidad de Navarra el año 1975.

Se inició en los estudios de flora y cartografía de la vegetación con la elaboración del Mapa de vegetación de Álava, publicado por la Diputación provincial en 1980. En los años siguientes visitó en repetidas ocasiones el herbario JACA para reconocer los entresijos de la organización y manejo del herbario, consultar dudas taxonómicas y, sobre todo, para recibir de Pedro Montserrat Recoder, a quien reconocía después como su único maestro, enseñanzas sobre la distribución y ecología de las plantas junto a retos y sugerencias para el trabajo «de campo» que iban a marcar su quehacer botánico.

Nada más terminar sus estudios universitarios se propuso «formar un herbario en el que se conservaran ordenadas las plantas que componen la flora actual del territorio alavés y de su entorno». Y este fue sin duda su gran afán y logro porque, a lo largo de más de 35 años de constante herborización e intercambio con otros

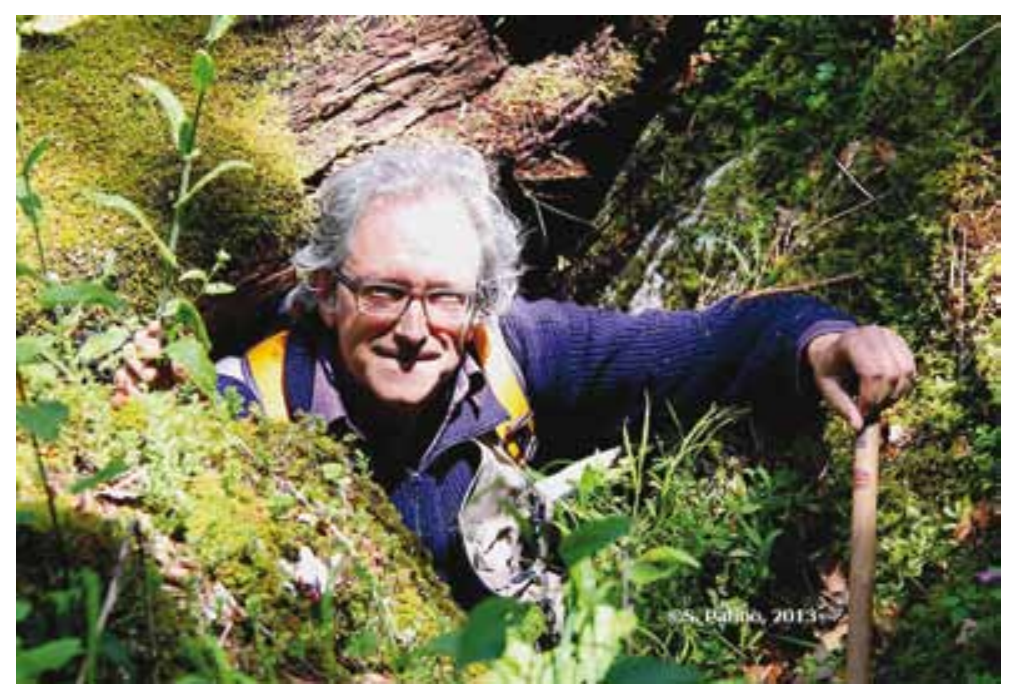

Pedro María Uribe-Echevarría en la Sierra de Entzia (Álava) en Junio de 2013. Fotografía de S. Patino en la web de la Asociación de Herbarios Ibero-Macaronésicos (AHIM). 
herbarios, reunió en el VIT 135.000 pliegos de nueve mil táxones, con 126 tipos que hoy se encuentran - preparados con esmero, ordenados e informatizados- en el Museo de Ciencias Naturales de Álava.

Sus más de 125 trabajos publicados incluyen numerosos estudios florísticos del País Vasco, Navarra y Aragón, iniciados con la Aproximación al catálogo florístico de Álava (publicado, junto a Juan Alejandre, en 1982). Esa obra constituyó el embrión del de Álava, Vizcaya y Guipúzcoa (1984) y, más tarde, de la Vegetación de la Comunidad Autónoma del País Vasco (1988) obras de las que fue principal impulsor. También encabezó las Claves ilustradas del País Vasco y territorio limítrofes y guió las magníficas ilustraciones realizadas por Iñaki Zorrakín. De sus trabajos taxonómicos, destacan sus estudios sobre narcisos y genistas que herborizó por toda la Península Ibérica y parte de Francia.

Hay que señalar también el amplio trabajo de cartografía de la vegetación, plasmado sobre todo en los mapas de toda la provincia alavesa a escala 1:25.000 que, junto a los del resto del País Vasco, fueron publicados por el Gobierno Vasco entre 1985 y 1987.

No escatimó tiempo para divulgar lo que sabía $\mathrm{y}$, en ese empeño, organizó y dirigió numerosos cursos, campañas y recorridos botánicos dirigidos a entusiastas de la observación de la naturaleza, fuera cual fuera su formación académica. Con lenguaje preciso y riguroso y notables dotes de comunica- ción, transmitió fácilmente su pasión y cautivó para la botánica a quienes sin duda le han de recordar.

Gustaba recalcar que si en algo avanzaba lo hacía caminando a hombros de los gigantes que habían sido «pioneros olvidados» de la botánica vasca e ibérica y para promover su reconocimiento, estudió a fondo la obra de Xabier de Arízaga y reconstruyó los «pasos hacia una flora del País Vasco», con motivo del homenaje a Pedro Montserrat (L'Atzavara, Mataró, 2007).

Una marcada personalidad, recta, austera y rebelde, le llevó a trabajar siempre «por su cuenta», muchas veces en solitario con no poco perjuicio para el desarrollo y difusión de su trabajo y privaciones en el entorno familiar que su mujer Carmen paliaba con determinación. Compensó muchas de esas limitaciones gracias a un tesón y una capacidad de trabajo fuera de lo común, tanto en sus interminables jornadas de campo como en el rastreo incansable de herbarios y bibliografía.

En su sobriedad, rechazaba elogios y hubiera deplorado verlos aquí reflejados. Sin embargo, quienes compartimos durante años tareas florísticas, los que continúan su labor botánica fuera y dentro del territorio vasco y quienes conocen el «trabajo oscuro» que se esconde tras una colección de plantas de semejante envergadura, aprecian el rigor de sus trabajos - muchos publicados en revistas humildes- y el valor del Herbario VIT que atesora el fruto de su esfuerzo denodado. Descanse en paz. 